\title{
Real-time Aerosol Measurements in Pilot Scale Coal Fired Post-combustion $\mathrm{CO}_{2}$ Capture
}

\author{
Chiranjib Saha ${ }^{a, *}$, James H. Irvin ${ }^{a}$
}

\begin{abstract}
Coal fired plants account for nearly $40 \%$ of the world's electric power generation and are a large source of $\mathrm{CO}_{2}$ emissions. Post-combustion $\mathrm{CO}_{2}$ capture using amine based solvents is a relatively mature technology. Recent pilot plants test data indicate that amine and its degradation produce emissions in the form of aerosols, which must be controlled for commercial success of this technology. In this study, the aerosols from $\mathrm{CO}_{2}$ depleted flue gas at the National Carbon Capture Center (NCCC) Pilot Solvent Test Unit (PSTU) and Slipstream Solvent Test Unit (SSTU) were measured using an isokinetic probe and a Dekati Electric Low Pressure Impactor $\left(\mathrm{ELPI}^{+\mathrm{TM}}\right)$. Multiple tests were conducted to quantify the effects of different process changes. PSTU measurements demonstrated sample sensitivity to transient intercooler start-up conditions, dilution gas temperatures and absorber beds in operation. During this test, the typical concentration (expressed in number of particles per volume) ranged from E+06 to E+07 $\mathrm{cm}^{-3}$ and the peak occurred near $0.12 \mu \mathrm{m}$ with an observed increase in sub $0.01 \mu \mathrm{m}$ aerosol concentration during transient intercooler start-up conditions. The measurements also demonstrated sample sensitivity to dilution gas temperatures by showing that aerosol size and concentration peaks shifted at higher diluter operating temperatures, especially above $100^{\circ} \mathrm{C}$. Several tests were also conducted at the absorber inlet and wash tower outlet of the SSTU with varying dilution ratios and temperatures. Comparison of SSTU and PSTU results are presented in this paper. The stage cuts for different impactor stages of different ELPI ${ }^{+}$instruments are calibrated which showed minimum deviation in the range of $0.02 \%$ to $0.70 \%$ from original calibration. Generally, the concentrations were higher at the absorber inlet compared to the wash tower outlet. Also, a higher concentration was observed for the smallest size fraction at the wash tower outlet compared to the absorber inlet. Similar to the PSTU, the concentration measured at the SSTU was in the range of E+06 $\mathrm{cm}^{-3}$. These results are promising and will enable the development of process control strategies to mitigate solvent losses and reduce operational and maintenance expenses.
\end{abstract}




\section{KEYWORDS}

Aerosols, $\mathrm{CO}_{2}$ capture, $\mathrm{ELPI}^{+}$, pilot plant

\section{INTRODUCTION}

Coal currently accounts for the $40 \%$ of world's electric power generation because it is an abundant fossil fuel and geographically well spread. This role of coal is expected to continue in the foreseeable future. Being carbon intensive, coal results in large $\mathrm{CO}_{2}$ emissions from power generations. There is a strong incentive to develop technologies that would allow more efficient $\mathrm{CO}_{2}$ capture from coal-fired plants under the current regulatory scenario. The three major approaches currently under investigation for $\mathrm{CO}_{2}$ capture are post-combustion, pre-combustion and oxy-combustion (World Energy Outlook, 2011). Post-combustion capture using amine scrubbing will most likely be the preferred technology because the technology is at a mature stage compared to the other two technologies (G. Rochelle, 2011) and also it can be retrofitted to the existing power plants in the near-to middle-term (José D. Figueroa, 2008; L.M. Romeo, 2008; Qi, 2011).

Amine based post-combustion $\mathrm{CO}_{2}$ capture makes use of the reversible nature of the chemical reaction of solvent (amine) with acid gas $\mathrm{CO}_{2}$ in an absorption-desorption process. Figure 1 shows the process flow diagram. However, this process is associated with certain losses of amine due to thermal and oxidative degradation, vapor emission and aerosol formation. Water wash after the absorber column has shown to be effective in reducing vapor emissions. However, controlling aerosol based solvent emissions requires detailed investigation (C. A. J. Mertens, P. Rogiers, L. Brachertb, P. Khakharia, E. Goetheer, K. Schaber, 2014; J. M. P. Khakharia, T. J. H. Vlugt, E. Goetheer, 2014) because recent pilot plant studies have shown that aerosol emissions can dominate the amine losses from the process (C. A. J. Mertens, P. Rogiers, L. Brachertb, P. Khakharia, E. Goetheer, K. Schaber, 2014). 


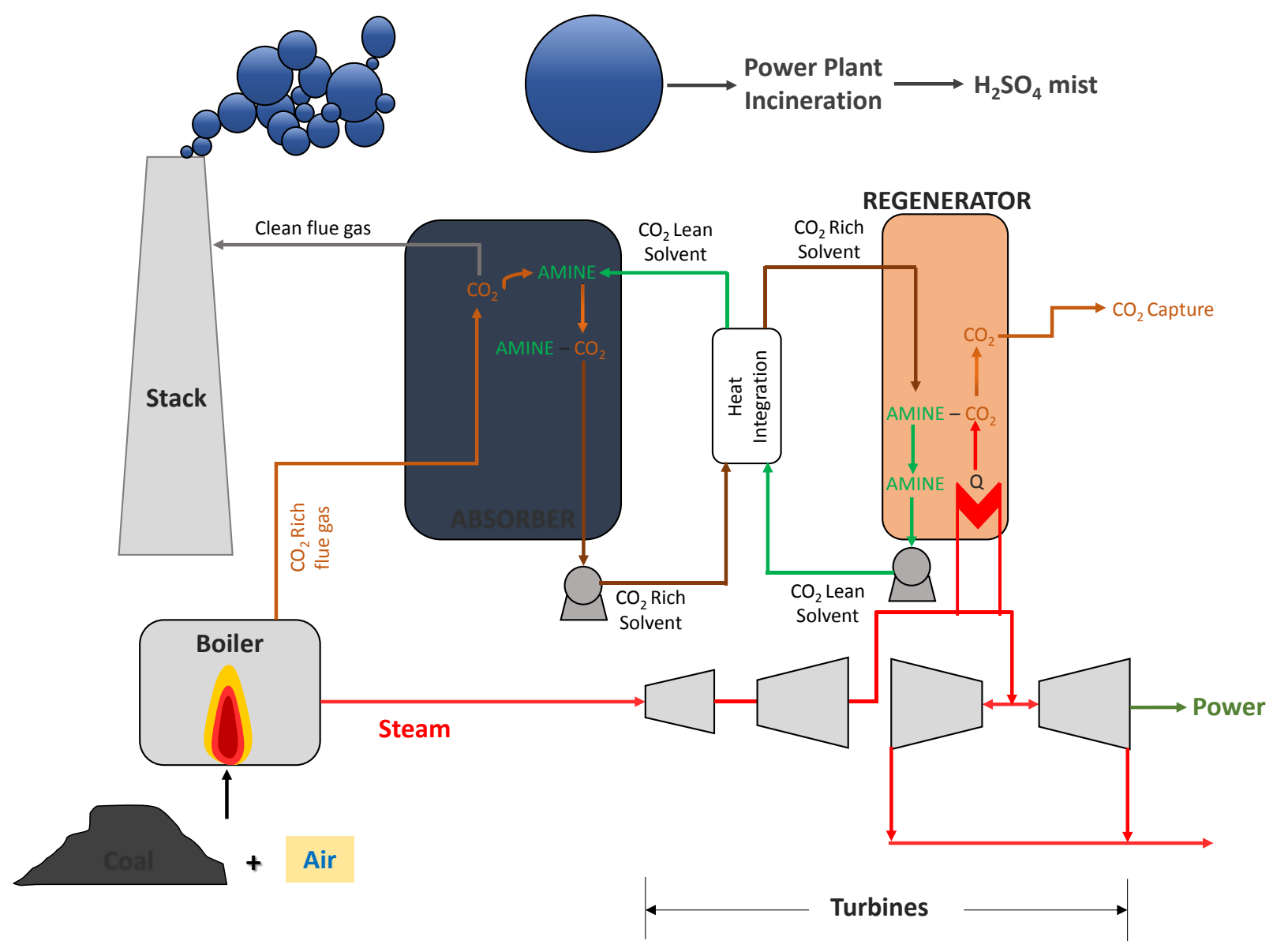

Figure 1. Schematic of post-combustion $\mathrm{CO}_{2}$ capture using amine

The aerosols are termed as smoke, fume, mist and fog formed as suspensions of liquid droplets with upper limits of $10 \mu \mathrm{m}$ in diameter (Schaber, 1995). The presence of sulfur in coal leads to the aerosol generation due to the reaction of water vapor and $\mathrm{SO}_{3}$ in flue gas that forms $\mathrm{H}_{2} \mathrm{SO}_{4}$ downstream of the combustion process (L. Brachert, 2014). $\mathrm{SO}_{3}$ is also formed from the catalytic oxidation of $\mathrm{SO}_{2}$ inside a Selective Catalytic Reduction (SCR) system during the reduction of the $\mathrm{NO}_{\mathrm{X}}$ (R. K. Srivastava, 2004). In wet flue gas desulfurization, temperature drops rapidly and super-saturation assists in converting incoming gaseous $\mathrm{H}_{2} \mathrm{SO}_{4}$ to homogeneous nucleation of aerosol droplets (L. Brachert, 2014). Therefore, designing countermeasures for aerosol emissions are crucial for cost-effective and environmentally benign commercial application of this technology.

Recently very few studies have been performed to measure the aerosol number concentration and size distribution at sub-pilot/pilot scale using $\mathrm{ELPI}^{+}$, phase doppler interferometers (PDI), and condensation particle counters (CPC)(E. Chen, 2014; C. A. J. Mertens, P. Rogiers, L. Brachertb, P. Khakharia, E. Goetheer, K. Schaber, 2014; L. B. J. Mertens, D. Desagher, B. Schallert, P. Khakharia, E. Goetheer, 2014; L. B. J. Mertens, D. Desagher, M. L. Thielens, P. Khakharia, E. 
Goetheerc, K. Schaber, 2014; L. Brachert, 2014; L. B. P. Khakharia, J. Mertens, A. Huizinga, B. Schallert, K. Schaber, T. J. H. Vlugt, E. Goetheer, 2013). Simulated flue gas with externally generated $\mathrm{SO}_{2} / \mathrm{H}_{2} \mathrm{SO}_{4}$ were mostly used. Moreover, the effect of real-time process changes during measurements were not extensively quantified. The details of the isokinetic aerosol sampling were not well reported. In this study aerosols are characterized using an ELPI from the coal combustion flue gas supplied to the PSTU and SSTU at the NCCC in Wilsonville, AL. The issues identified above in literature are addressed to develop a robust set of results that will help to design countermeasures. The results reported in this paper are for generic MEA solvent. For a specific solvent, further aerosol characterization will be needed.

\section{PILOT PLANT DESCRIPTION AND METHODS}

The aerosol size distributions and concentrations under different operating conditions were measured at the PSTU and the SSTU using isokinetic probes and a Dekati ELPI ${ }^{+}$. In this section, a brief description of the pilot plants, operating conditions, sampling set-up and ELPI ${ }^{+}$analyzer systems are briefly described.

\subsection{Pilot Solvent Test Unit (PSTU)}

The process flow diagram of the Pilot Solvent Test Unit (PSTU) at the National Carbon Capture Center (NCCC) is shown in Figure 2 (DOE Report, 2012). The coal-fired flue gas is provided by Unit 5 of the Alabama Power E.C. Gaston Power Plant. Up to 35,000 lb/hr of flue gas is extracted downstream of the Wet Flue Gas Desulfurization (WFGD) system from Unit 5 and nominally 5,000 lb/hr [ 0.5 Megawatt (MW)] of flue gas flows to the absorber of the PSTU (DOE Report, 2012). There are five major columns, or subsystems, which include (DOE Report, 2012):

- The pre-scrubber which removes the small amount of $\mathrm{SO}_{2}$ remaining in the flue gas

- A cooler/condenser unit that cools the flue gas to appropriate reaction temperatures and removes flue gas moisture

- An absorber to promote efficient gas-liquid contacting to remove $\mathrm{CO}_{2}$ from the flue gas

- A washing tower that cools the $\mathrm{CO}_{2}$-depleted flue gas, removing trace amounts of entrained solvent

- A regenerator that provides heat to release the $\mathrm{CO}_{2}$ from the solvent

Isokinetic samples for aerosol measurements using the $\mathrm{ELPI}^{+}$were extracted from the wash tower outlet. 


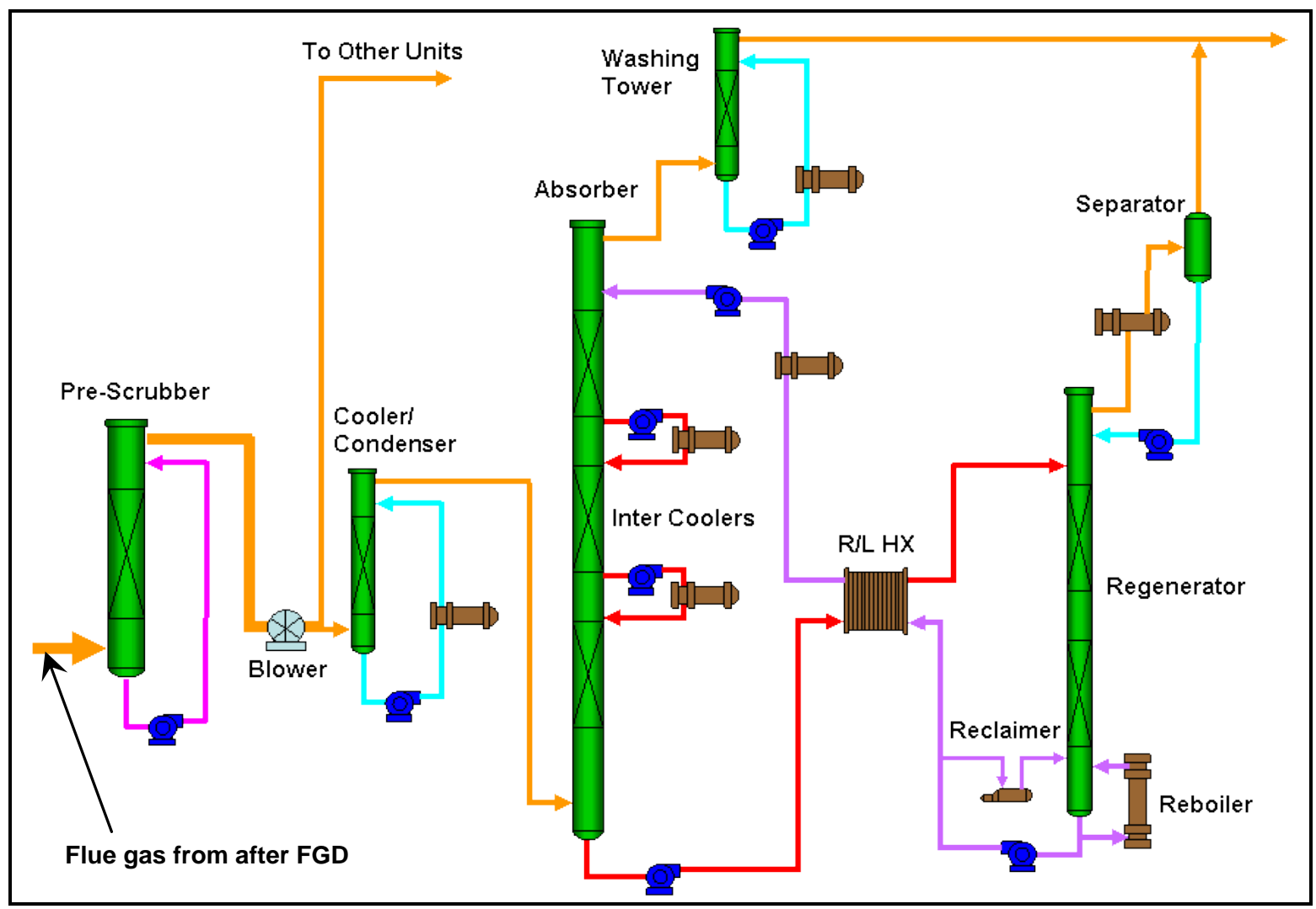

Figure 2. Simplified process flow diagram of PSTU

FGD - Flue Gas Desulphurization, R/L HX - Rich/Lean Heat Exchanger

\subsection{Slipstream Solvent Test Unit (SSTU)}

The Slipstream Solvent Test Unit (SSTU) was installed at the NCCC to increase the flexibility of the post-combustion $\mathrm{CO}_{2}$ facilities by allowing testing of solvents less than 4,000 gallons (required for the PSTU) at relatively smaller scale than PSTU. Similar to the PSTU, the SSTU comprises an absorber, regenerator, wash tower and associated equipment along with analytical instrumentation. The operation of the unit was started in 2015 (DOE Final Report, 2014). Figure 3 provides a simplified process diagram of the SSTU. 


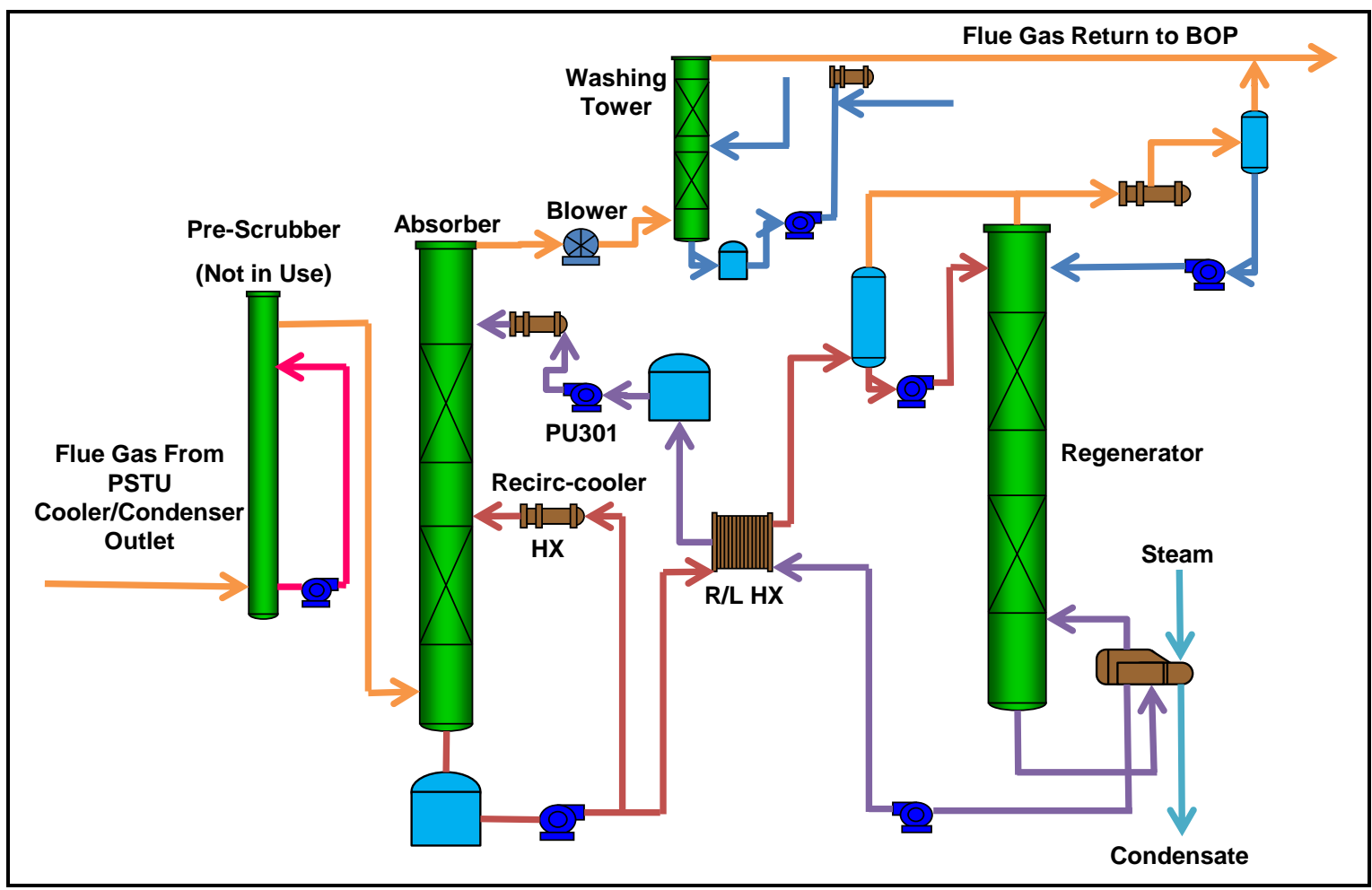

Figure 3. Simplified process flow diagram of SSTU

PSTU - Pilot Solvent Test Unit, R/L HX - Rich/Lean Heat Exchanger, HX - Heat Exchanger, BOP - Balance of Plants, PU301 - Specific pump number from process and instrumentation diagram

The PSTU and the SSTU are fully integrated systems for comprehensive solvent characterization at pilot-scale and at bench-scale respectively (DOE Final Report, 2014). The SSTU is about one tenth the size of the PSTU. Nominally $500 \mathrm{lb} / \mathrm{hr}(\sim 0.05 \mathrm{MW})$ of flue gas flows to the absorber of the SSTU from the PSTU cooler. Isokinetic samples for aerosol measurements using the $\mathrm{ELPI}^{+}$were extracted from the absorber inlet and wash tower outlet of the SSTU to characterize the change in real-time aerosols generated.

The details of the measurement set-up are described in the next section 2.3. It should be noted that the tests at the PSTU were conducted in early 2015. Some of the modifications in the measurement set-up, for example, new design of the dilution probe and use of heated $\mathrm{ELPI}^{+}$ stages, were incorporated prior to the test runs at the SSTU in late 2015. These changes are also discussed in the next section 2.3.

\subsection{Sample Extraction Systems}

The schematic of the ELPI ${ }^{+}$measurement set-up at the Wash Tower Outlet (WTO) of the PSTU is shown in Figure 4. Because the sample stream at the WTO is expected to be saturated, dilution 
of the sample with heated air is necessary to avoid condensation on the impactor plates of the $\mathrm{ELPI}^{+}$stages. The condensation can lead to electrical short circuiting of the plates and erroneous measurements of aerosol size distribution and concentrations.

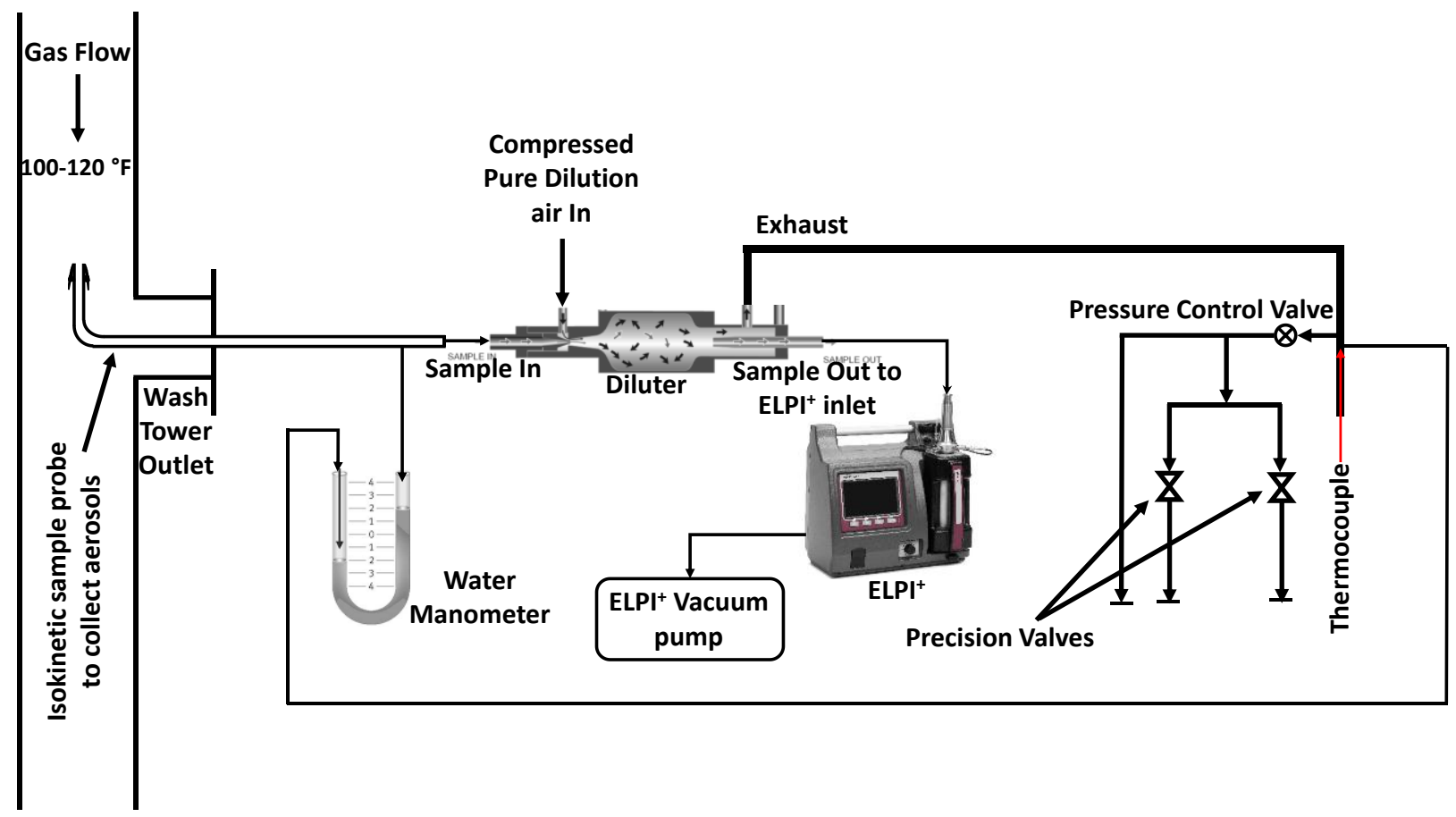

\section{Figure 4. Schematic of the isokinetic sample extraction system for ELPI ${ }^{+\mathrm{TM}}$ measurements at wash tower outlet of PSTU}

An ejector type dilutor is used. The dilution air is passed through a moisture trap and filter to dry the air and collect any particles. The dilution air is heated and the diluted samples from the outlet of the dilution chamber is drawn to an $\mathrm{ELPI}^{+}$for aerosol characterization. The dilution ratio is defined by Equation 1 ("DEKATI® Diluter User Manual: Ver. 5.1," 2014).

$N=\frac{V_{\text {sample }}+V_{\text {air }}}{V_{\text {sample }}}$

Where $\quad \begin{array}{ll}\mathrm{N} & \text { = Dilution ratio } \\ \mathrm{V}_{\text {sample }} & \text { = Sample volume flow } \\ \mathrm{V}_{\text {air }} & \text { = Air volume flow }\end{array}$

In an ejector type dilutor, the flow ratio (and thus the dilution ratio) is automatically kept constant over a wide operation range as long as the sample pressure is constant. The initial concentration of the sample is calculated by multiplying the diluted sample concentration with the dilution ratio N ("DEKATI® Diluter User Manual: Ver. 5.1," 2014). 
The High Temperature (HT) ELPI $^{+}$system was installed for aerosol characterization at the absorber inlet and wash tower outlet of the SSTU as shown in Figure 5. It should be noted that a custom made dilutor was used instead of an ejector type dilutor. In an ejector type dilutor, a critical orifice is used to control the dilution air flow. The pressure drop through the orifice helps to draw the sample to the dilution chamber. The inlet pressure at dilutor has to be kept constant slightly more than atmospheric pressure to ensure constant pressure drop across the dilutor and prevent back flow of the sample from the dilutor to the sample nozzle. Maximum flow is fixed for a particular pump. Therefore, the outlet pressure from the ejector type dilutor is also fixed to achieve the constant pressure drop. However, there is a chance of change in process pressure drop and hence the gas stream velocity. But if ejector type dilutor is used, there is a less flexibility of choosing different sample extraction nozzles to accommodate for any change in this velocity. Moreover, due to the presence of restrictions in the form of critical orifice in ejector type dilutor, there is a chance of small amount of aerosol sample destruction on its way to ELPI sampling system. This sample destruction is although anticipated to be very small in quantity by Dekati Ltd. During PSTU tests, we have carefully calculated the pressure drops across the ejector type dilutor (critical orifice) and choose the sample extraction nozzle. To avoid these limitations, we have designed carefully the custom made dilutor that is capable of sampling aerosol emissions with different sampling nozzles to account for different process stream velocities. This dilutor also has minimum restriction points that allow for non-destruction aerosol emission as much as possible. Thus the use of the custom made dilutor and $\mathrm{HT} \mathrm{ELPI}^{+}$ensured representative sample extraction.

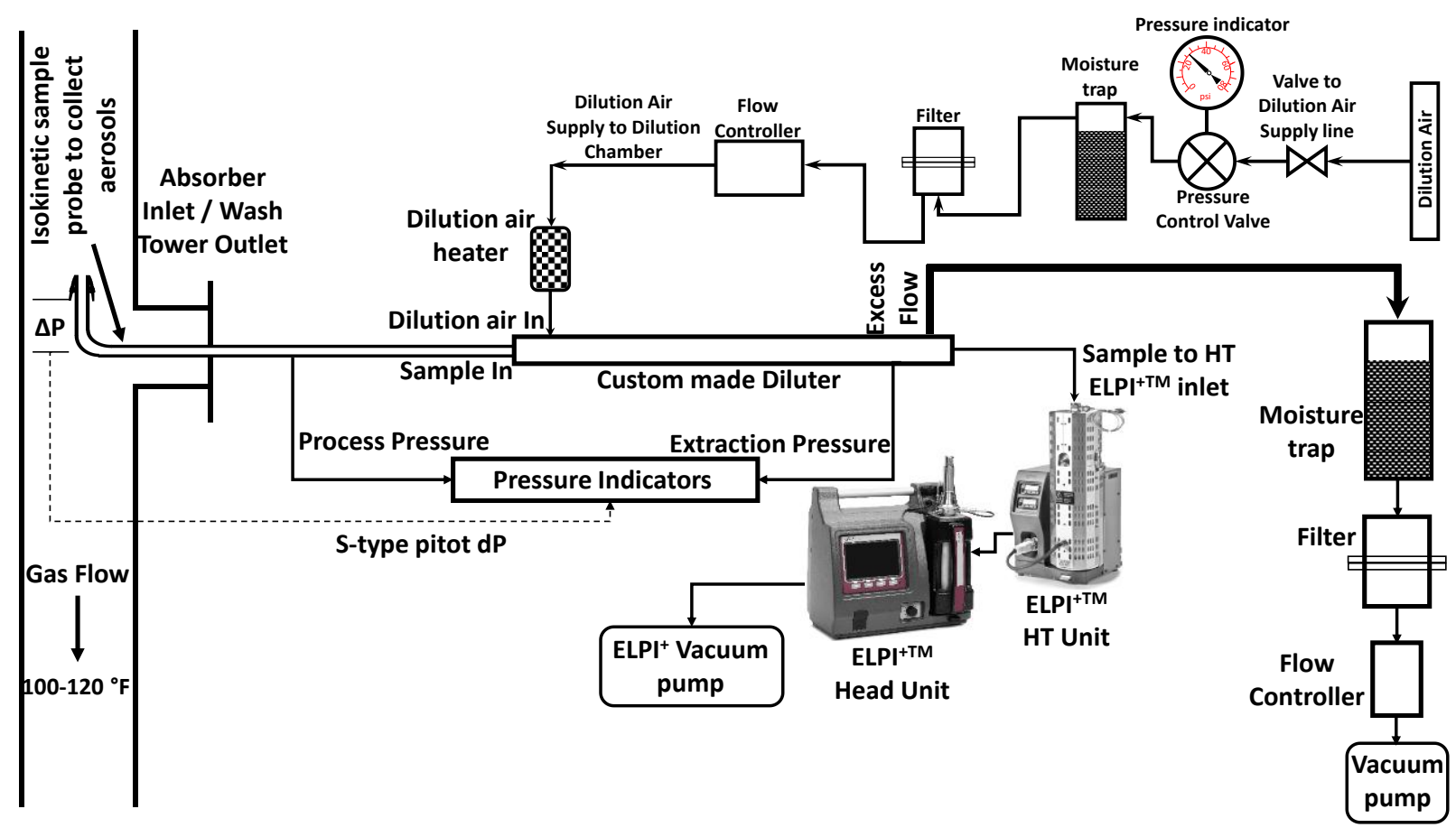

Figure 5. Schematic of the isokinetic sample extraction system for HT ELPI measurements at absorber inlet / wash tower outlet of SSTU 


\subsection{PSTU and SSTU Operating Parameters}

Typical operating parameters for the two test units during ELPI+ testing are listed below in Table 1.

Table 1. Operating Parameters

\begin{tabular}{lll}
\hline Operating Parameters & PSTU & SSTU \\
\hline Absorber Flue Gas Flow Rate (G), lb/hr & 4,400 & 405 \\
Solvent Flow Rate (L), lb/hr & 20,000 & 950 \\
Re-boiler Steam Flow Rate $(\mathrm{S}), \mathrm{lb} / \mathrm{hr}$ & 1,434 & 125 \\
Absorber Inlet Flue Gas Temperature, ${ }^{\circ} \mathrm{F}$ & 110 & 123 \\
Absorber Inlet Solvent Temperature, ${ }^{\circ} \mathrm{F}$ & 106 & 104 \\
Wash Tower Exit Temperature, $^{\circ} \mathrm{F}$ & 115 & 75 \\
Regenerator Pressure, psig & 14 & 15 \\
Inlet Flue Gas $\mathrm{CO}_{2}$ Content, vol\% & 12 & 11 \\
Number of Absorber Beds & 1,2 and 3 & 1 and 2 \\
Number of Intercoolers & 2 & 1 \\
\hline
\end{tabular}

\subsection{Dekati Electrical Low Pressure Impactor (ELPI $\left.{ }^{+}\right)$}

Real-time measurements of size distribution and concentration for 0.006 to $10 \mu \mathrm{m}$ aerosols are possible using the ELPI ${ }^{+}$. The operating principle of the ELPI ${ }^{+}$is based on the fact that the particles are first charged to a known level in a corona charger. According to their aerodynamic diameter, the particles are size classified in a low-pressure cascade impactor after charging. Electrometers are connected to each impactor stage which is electrically insulated. The electrometer of each impactor stage records an electrical current as produced by charged particles collected on the stage. This current is proportional to the concentration of particles on each stage. Figure 6 describes the operating principle of the ELPI' ("ELPI+TM User Manual: Ver. 1.50," 2015).

There are 13 impactor stages and one filter stage that collect aerosol/particle samples in the range of $6 \mathrm{~nm}$ to $10 \mu \mathrm{m}$. The particle size collection range of the impactor stages is $17 \mathrm{~nm}$ to $10 \mu \mathrm{m}$, and the filter stage reduces the particle size from $17 \mathrm{~nm}$ to $6 \mathrm{~nm}$. Nominal sample flow is $10 \mathrm{~L} / \mathrm{min}$ at temperatures below $60^{\circ} \mathrm{C}$. However, the SSTU tests were performed using $\mathrm{HT}_{\mathrm{ELPI}}{ }^{+\mathrm{TM}}$ which has three different temperature settings $\left(60^{\circ} \mathrm{C}, 120^{\circ} \mathrm{C}\right.$, and $\left.180^{\circ} \mathrm{C}\right)$. SSTU tests were conducted at the $60^{\circ} \mathrm{C}$ setting. The ambience of the ELPI ${ }^{+\mathrm{TM}}$ should be $10-35^{\circ} \mathrm{C}$ with relative humidity of up to $90 \%$. Pressure under the first stage is $40 \mathrm{mbar}$ and the pump for $10 \mathrm{~L} / \mathrm{min}$ ELPI+ should draw a minimum of $16 \mathrm{~m}^{3} / \mathrm{h}$ at $40 \mathrm{mbara}$, although the recommended value is $25 \mathrm{~m}^{3} / \mathrm{h}$ at $40 \mathrm{mbar}$. 


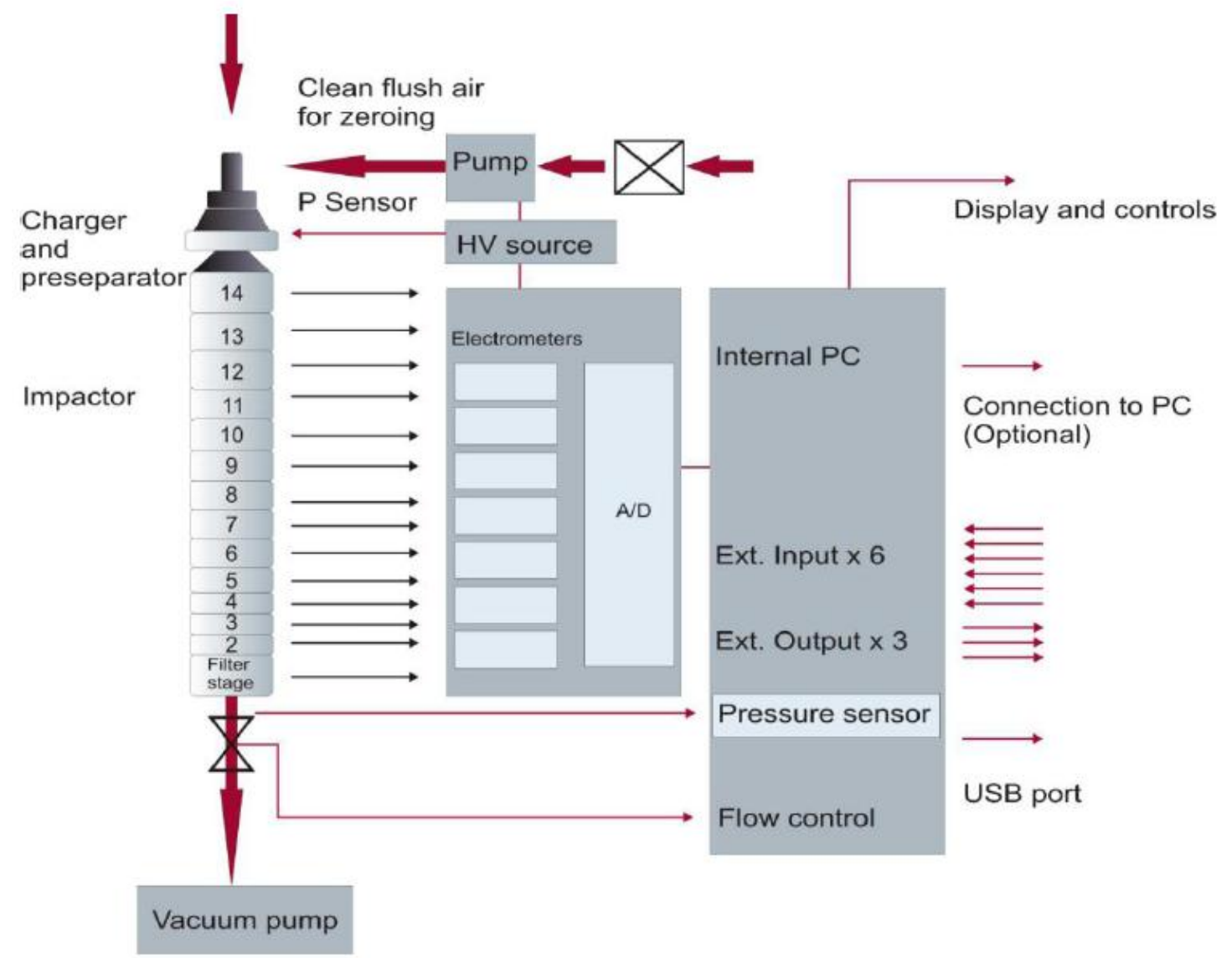

Figure 6. Operating principle of DEKATI ELPI ${ }^{+\mathrm{TM}}$

Different impactor stages are used for particle size fractioning. Each ELPI ${ }^{+}$unit is shipped with a unique impactor serial number and is calibrated with D50\% stage cut points with aerodynamic diameters by Dekati. However, the pressure and temperatures on a particular day may differ slightly from the calibration pressure and temperatures. Therefore, the stage cut points are corrected for each test day. If wrong values have been used during the measurement, the data should be recalculated with correct values using the ELPI ${ }^{+}$data file filter program. The maximum variation of new calibration values based on each test day's condition from the original calibrated values of the stage cuts was between $0.02-0.70 \%$, which is considered acceptable according to the manufacturer.

\section{RESULTS AND DISCUSSIONS}

The results of aerosol measurements from the PSTU and the SSTU are reported in this section. The effect of aerosol concentrations and size distributions under different test conditions such as dilution ratio, temperature and other test parameters are discussed in this section. 


\subsection{PSTU Tests}

The real-time ELPI ${ }^{+}$measurements were taken at the WTO of the PSTU. Tests were conducted on three different days to investigate the effects of different test conditions such as dilution temperature and use of intercoolers and absorber beds.

Figure 7 represents the effect on total particle number concentration as measured real-time by $\mathrm{EPLI}^{+}$on test day 2. The $\mathrm{X}$-axis represents the total test duration, primary $\mathrm{Y}$-axis represent combined number concentration of all stages and secondary $\mathrm{Y}$-axis represent some of the absorber process parameters. It can be seen from this figure that the $\mathrm{CO}_{2}$ and $\mathrm{H}_{2} \mathrm{O}$ concentration at the absorber inlet were almost constant during the test period. The aerosol number concentration was generally in the range of E+06 to E+07 $\mathrm{cm}^{-3}$. These results are in agreement with literature results (C. A. J. Mertens, P. Rogiers, L. Brachertb, P. Khakharia, E. Goetheer, K. Schaber, 2014; R. K. Srivastava, 2004). As indicated by the absorber temperature profiles, both intercoolers were turned on for two different periods (from 0:30 to 2:25 and 3:50 to 4:15 hours of total test time). The intercoolers strongly influenced the particle concentrations, which generally decreased with decreasing absorber temperature.

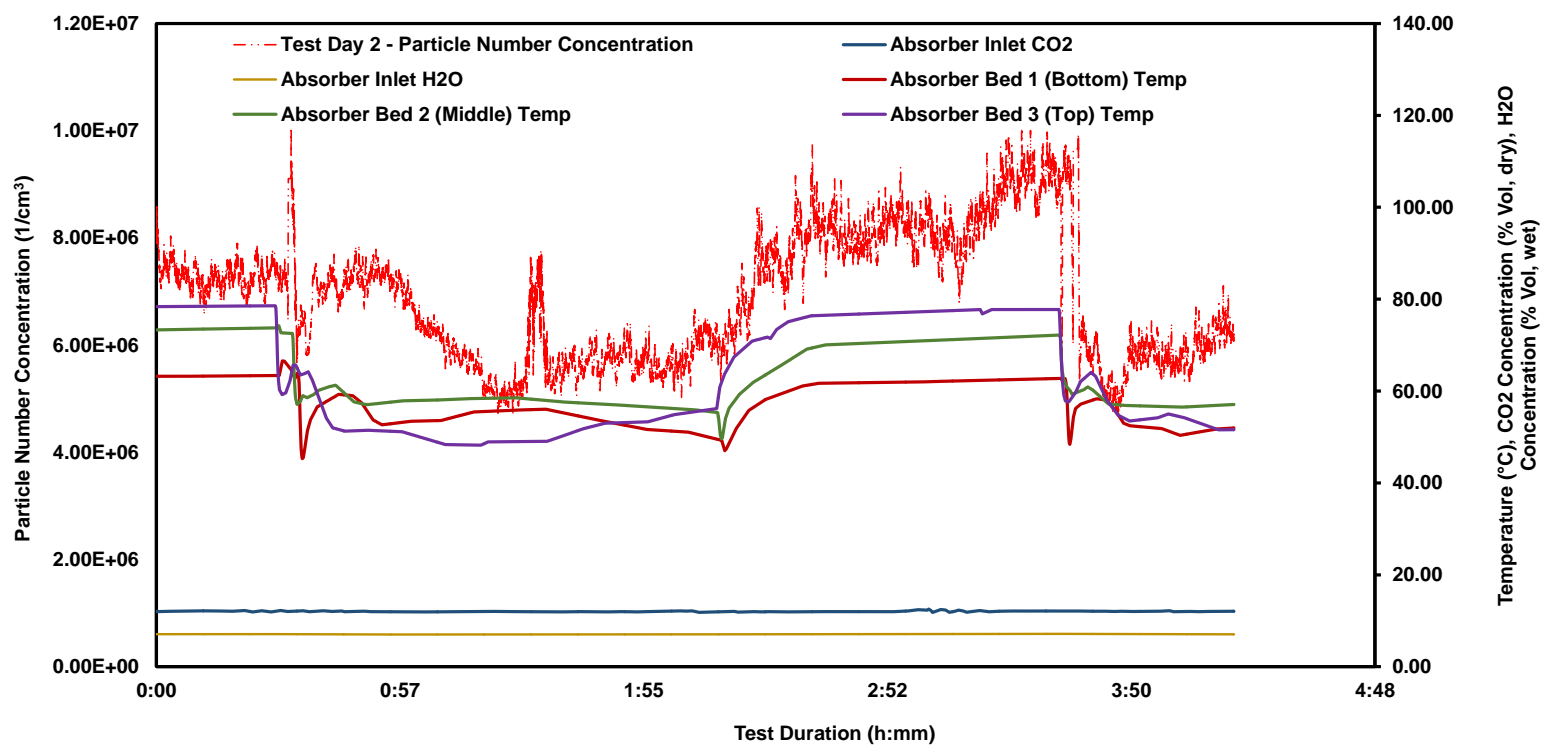

Figure 7. Real-time ELPI ${ }^{+}$measurements of aerosol concentrations with varying absorber temperatures

The color-coded intensity graphs in Figure 8 display the particle size distribution as a function of time. $\mathrm{X}, \mathrm{Y}$ and $\mathrm{Z}$ axes show the time, particle size and the concentration respectively. The bottom two graphs provide the number concentrations as functions of particle sizes. The particle sizes in these graphs are the aerodynamic sizes. A large number of aerosols with relatively higher size can be seen from the intensity and number concentration (left hand side one) plots when both the absorber intercoolers were off or not under operation. A plume of mist or aerosols was evident in the smallest size range immediately after the intercoolers were turned on as can be 
seen from the intensity and number concentration (right hand side one) plots. As time progressed, the aerosol concentration at smallest size (shown in figure at the right hand side) moved towards relatively higher size and the effect of turning the intercoolers on aerosol concentration settles down. The total number concentration also decreases when both intercoolers operated.

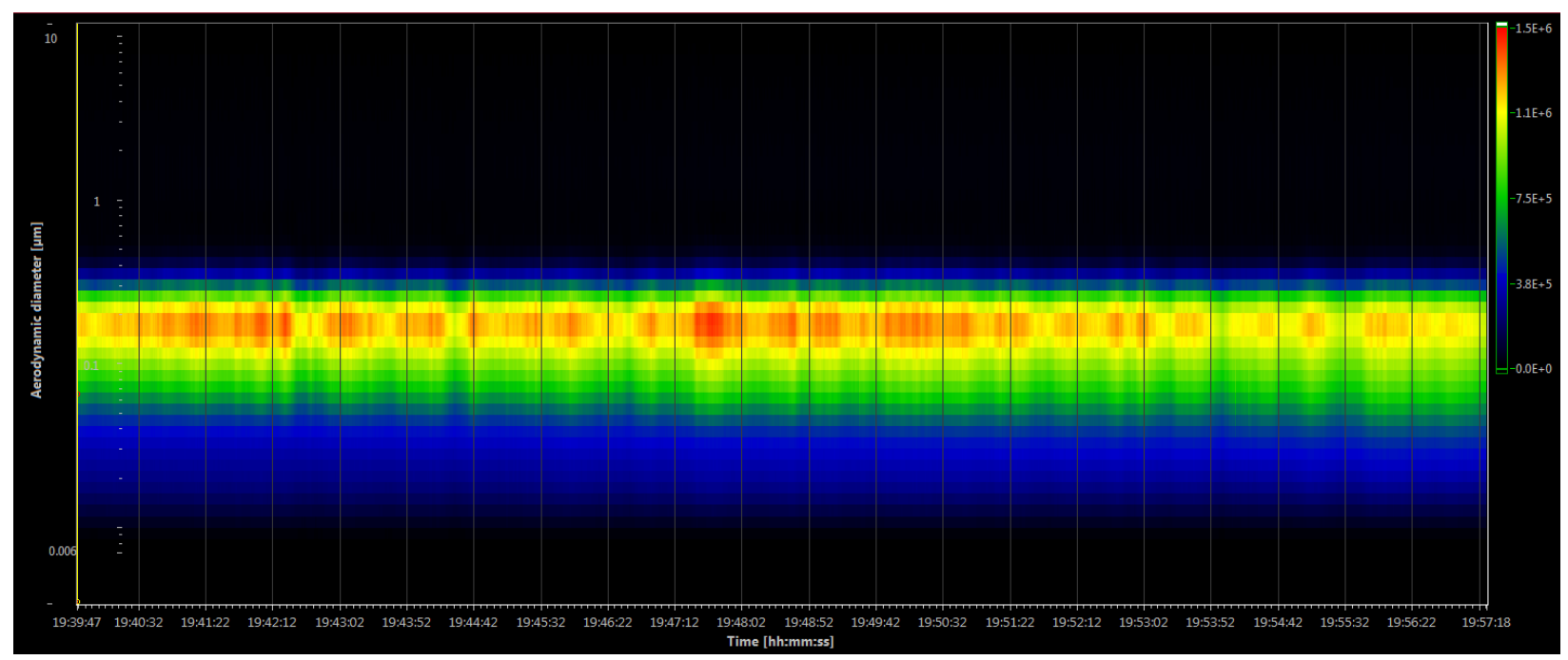

Intercoolers Off (intensity plot)

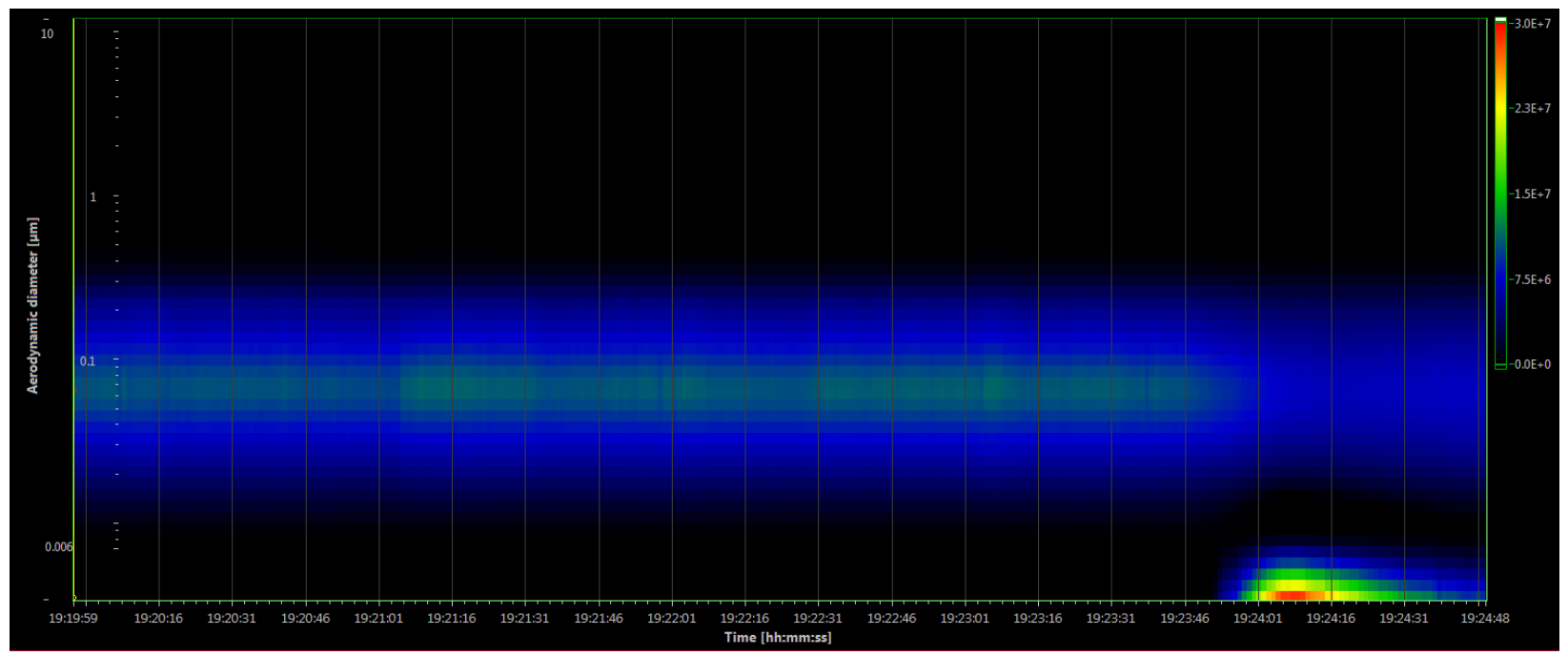

Intercoolers On (intensity plot) 


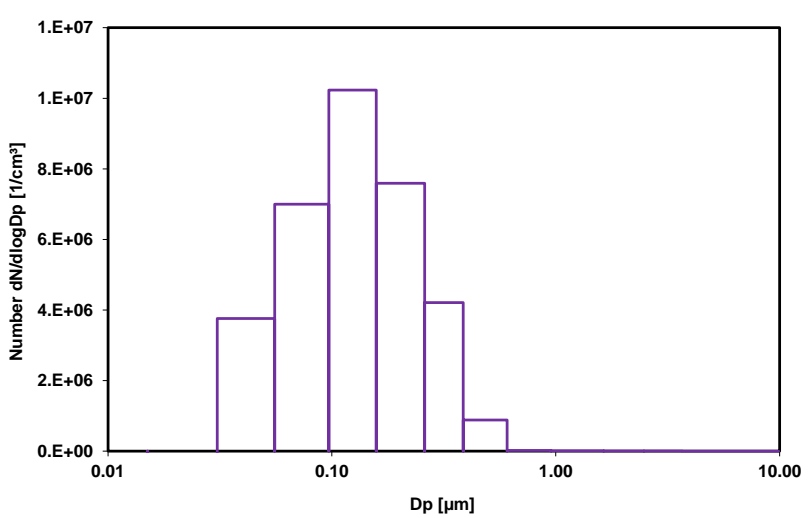

Intercoolers Off (no. conc.)

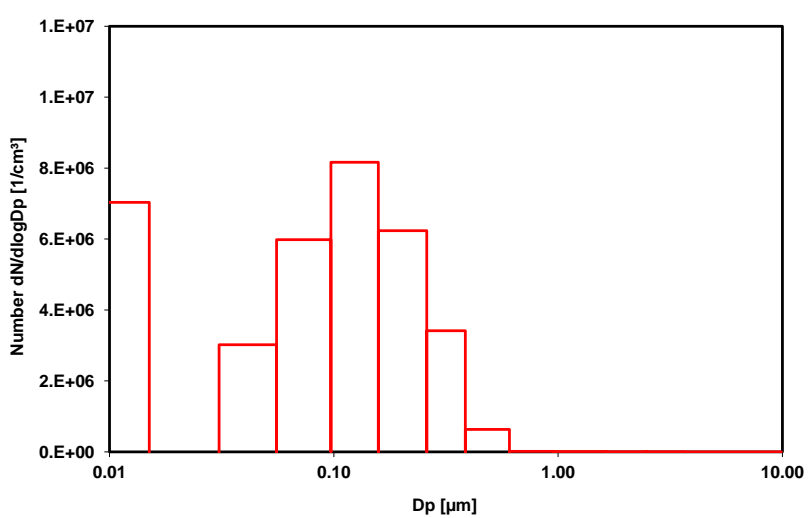

Intercoolers On (no. conc.)

Figure 8. Real-time aerosol intensity \& number concentrations (no. conc.) measured by $\mathrm{ELPI}^{+\mathrm{TM}}$ before and after intercoolers turned on

The real-time aerosol number concentrations at the highest dilution temperature of $180^{\circ} \mathrm{C}$ were measured on test day 1. These results are compared with the lower dilution temperature aerosol concentration measurements on test day 2 at $90^{\circ} \mathrm{C}$ in Figure 9. A clear shift of higher number concentration towards lower sizes at the high dilution temperature can be seen. This size change is likely related to accelerated evaporation due to low relative humidity and elevated temperature of the aerosols. The larger aerosols may separate into very small aerosols and contribute to this high number concentration at the lowest size fraction. Therefore, it can be concluded that for an ejector type dilutor, the temperature above the condensation point should be high enough that the aerosols are not vaporized or burst into very small size that is hard to capture.
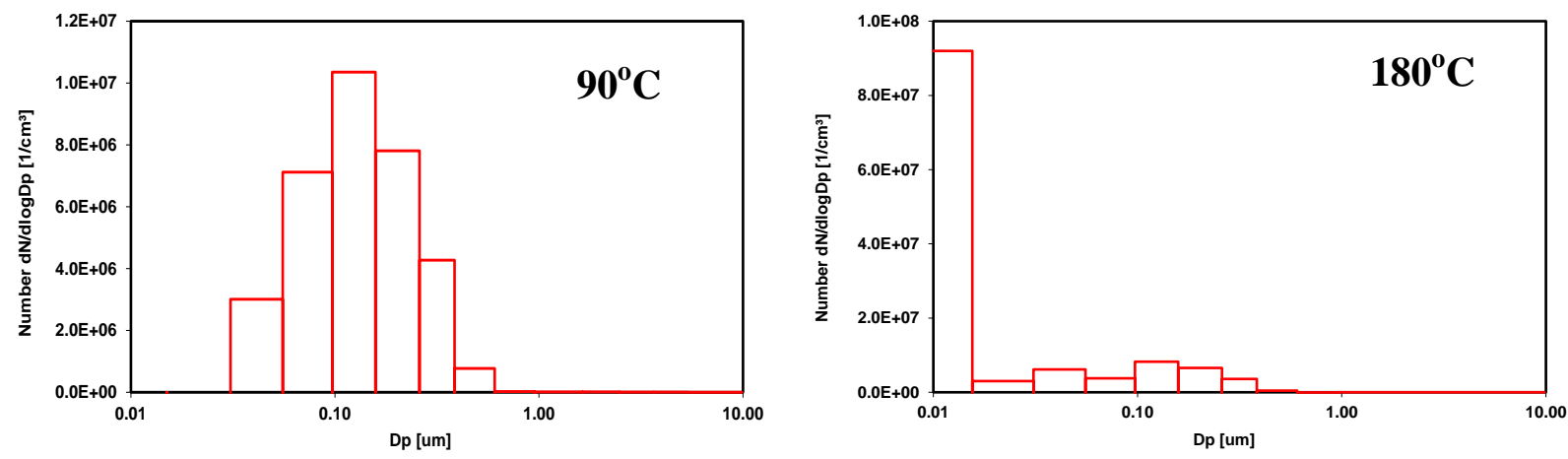

Figure 9. Effect of dilution heating temperature on real-time ELPI ${ }^{+}$measurements of aerosol number concentrations

The effect of number of absorber beds under operation on particle number concentrations was also investigated in real-time using the ELPI ${ }^{+}$. Figure 10 shows the particle number concentration of each stage plotted over the test duration. As soon as the third bed was turned on, the number concentration of each stage reached a new, higher value and remained at around this value until the third bed was turned off. 


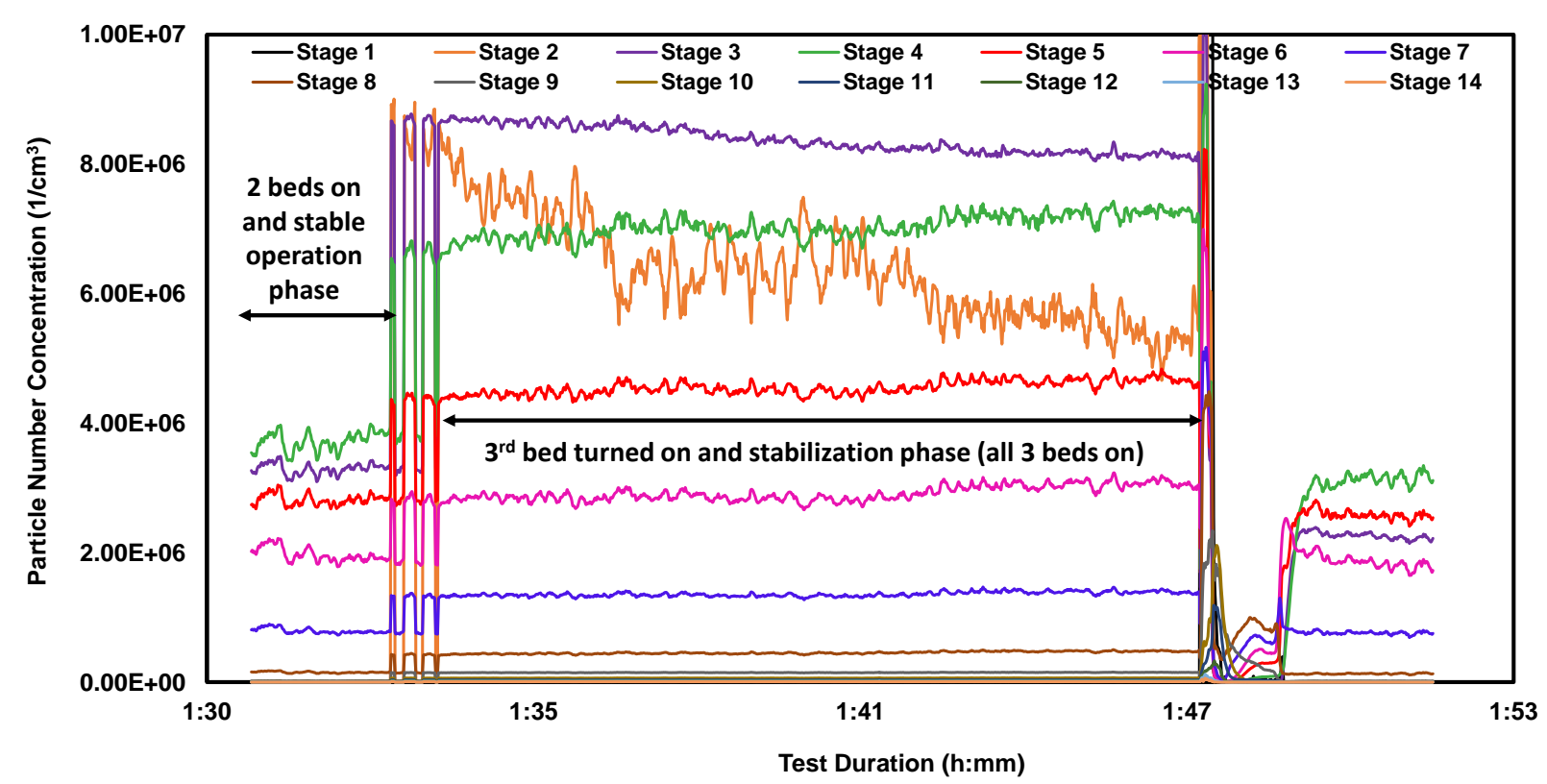

Figure 10. Real-time ELPI ${ }^{+}$measurements of absorber bed effects on aerosol number concentrations

Further, the number concentration graphs (Figure 11) for two and three absorber beds in operation show that the aerosol number concentration for two beds ranged between $0.04-0.40 \mu \mathrm{m}$ aerodynamic diameters and for three beds were 0.02 to $0.8 \mu \mathrm{m}$. The cumulative number concentration was about twice as high with three beds than with two. All three beds are similar and contain structured packing. It is possible that the third bed, when not in operation, may act as a demister due to the compact design which helps to knock out most of the smallest aerosols and perhaps half of the larger aerosols. However, detailed investigation in future test campaigns is necessary for definite conclusions.

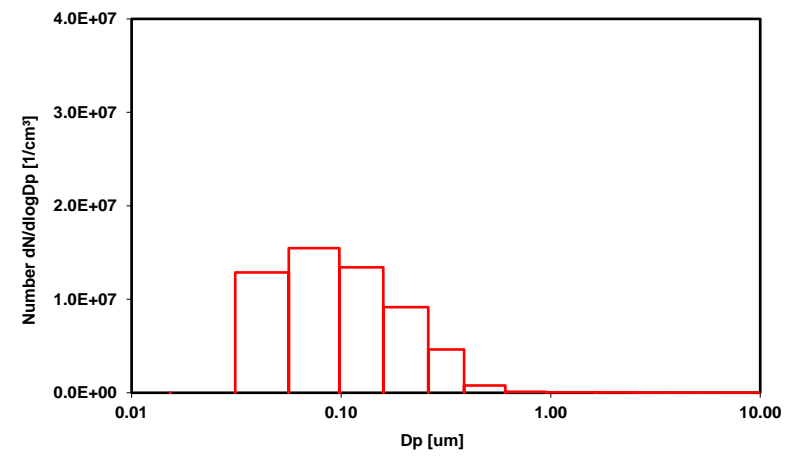

Two beds

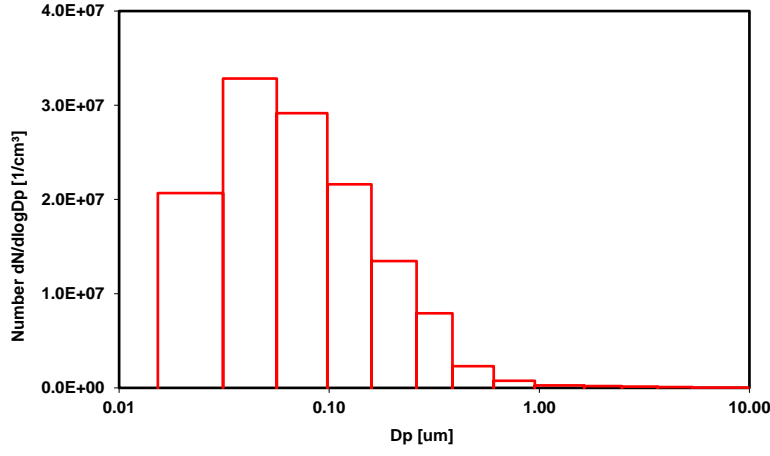

Three beds

Figure 11. Effect of number of beds under operation on real-time aerosol number concentrations 


\subsection{SSTU Tests}

Figure 12 shows the real-time ELPI $^{+}$measurements of aerosol number concentrations and cumulative percentages at the absorber inlet and wash tower outlet. The process and physical conditions (dilution ratio, dilution heating temperature, gas flow rate, isokinetic nozzle size, HT$\mathrm{ELPI}^{+}$temperature set points, etc.) were kept consistent for the two sets of measurements. As expected, the aerosol concentration was much lower at the wash tower outlet than at the absorber inlet. The aerosol cumulative percentage plots indicate that the smaller size aerosols at the absorber inlet were captured in the wash tower. It can be seen that around $10-12 \%$ of very small size aerosols can be captured at WTO compared to Absorber Inlet at SSTU.

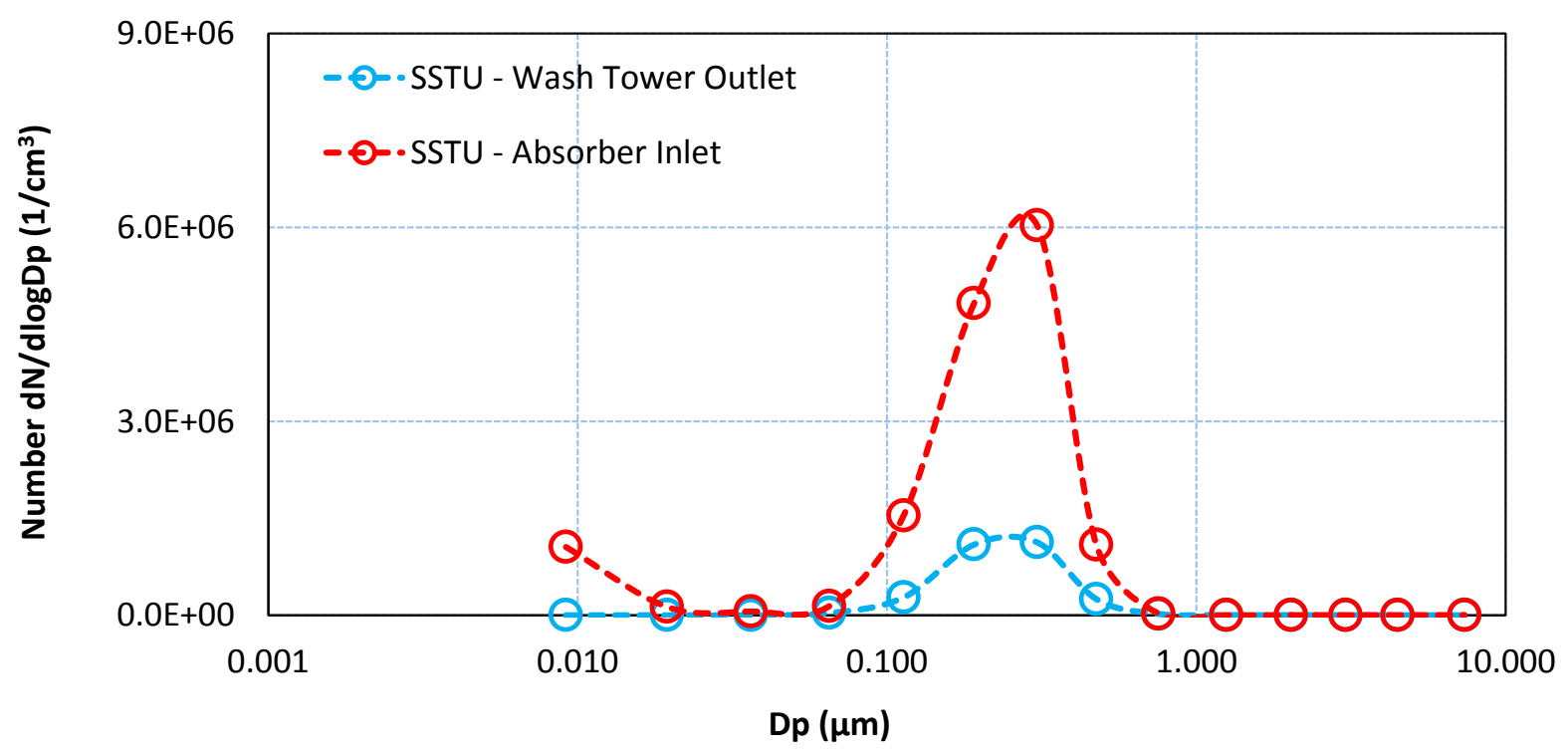




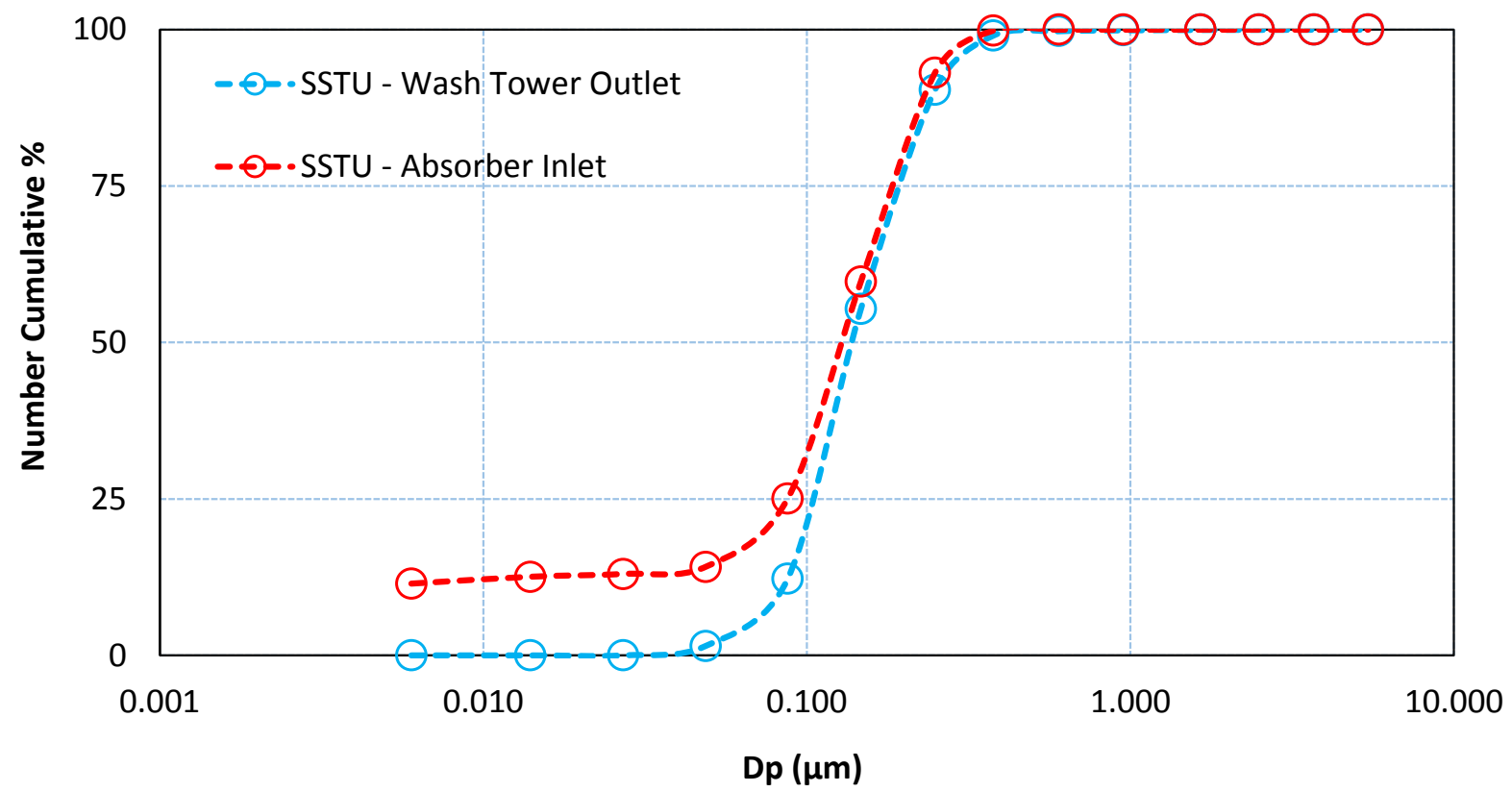

\section{Figure 12. Real-time ELPI ${ }^{+}$measurements of aerosol number concentrations \& cumulative percentage at absorber inlet and wash tower outlet}

The effect of dilution air heating temperature at the WTO of the SSTU is plotted in Figure 13. For PSTU, the dilution temperatures considered for investigation were $90^{\circ} \mathrm{C}$ and $180^{\circ} \mathrm{C}$. The results are explained in Figure 9 under the previous section 3.1. The dilution heating temperatures of $65^{\circ} \mathrm{C}$ and $90^{\circ} \mathrm{C}$ were chosen for the SSTU tests based on the dew point temperature of the incoming gas at the particular water vapor partial pressure. It can be seen from the figure that at higher dilution temperature there is a tendency of generation of lower size aerosols. This observation is similar to PSTU data in Figure 9. However, there is a basic difference between the SSTU and PSTU results. The higher dilution temperature of $180^{\circ} \mathrm{C}$ at PSTU led to more generation of the lowest size aerosols at the PSTU WTO. However, in the SSTU tests, only $30 \%$ of larger size aerosols at $65^{\circ} \mathrm{C}$ were converted to smaller size aerosols at $90^{\circ} \mathrm{C}$. The overall characteristics of the number concentration in the size range of $0.02-0.76 \mu \mathrm{m}$ are very similar for both cases. The cause of the lower size aerosol concentration at lower dilution temperature, whether from evaporation due to low relative humidity or from process changes or both, is to be further investigated. Nevertheless, the information obtained is very important in that it proved that dilution temperature just above dew point temperature is sufficient for characterizing aerosols without artifacts. From the cumulative plot, it can be quantified that around 30\% of large size aerosols evaporates to very small size aerosols due to the effect of high dilution temperature. 

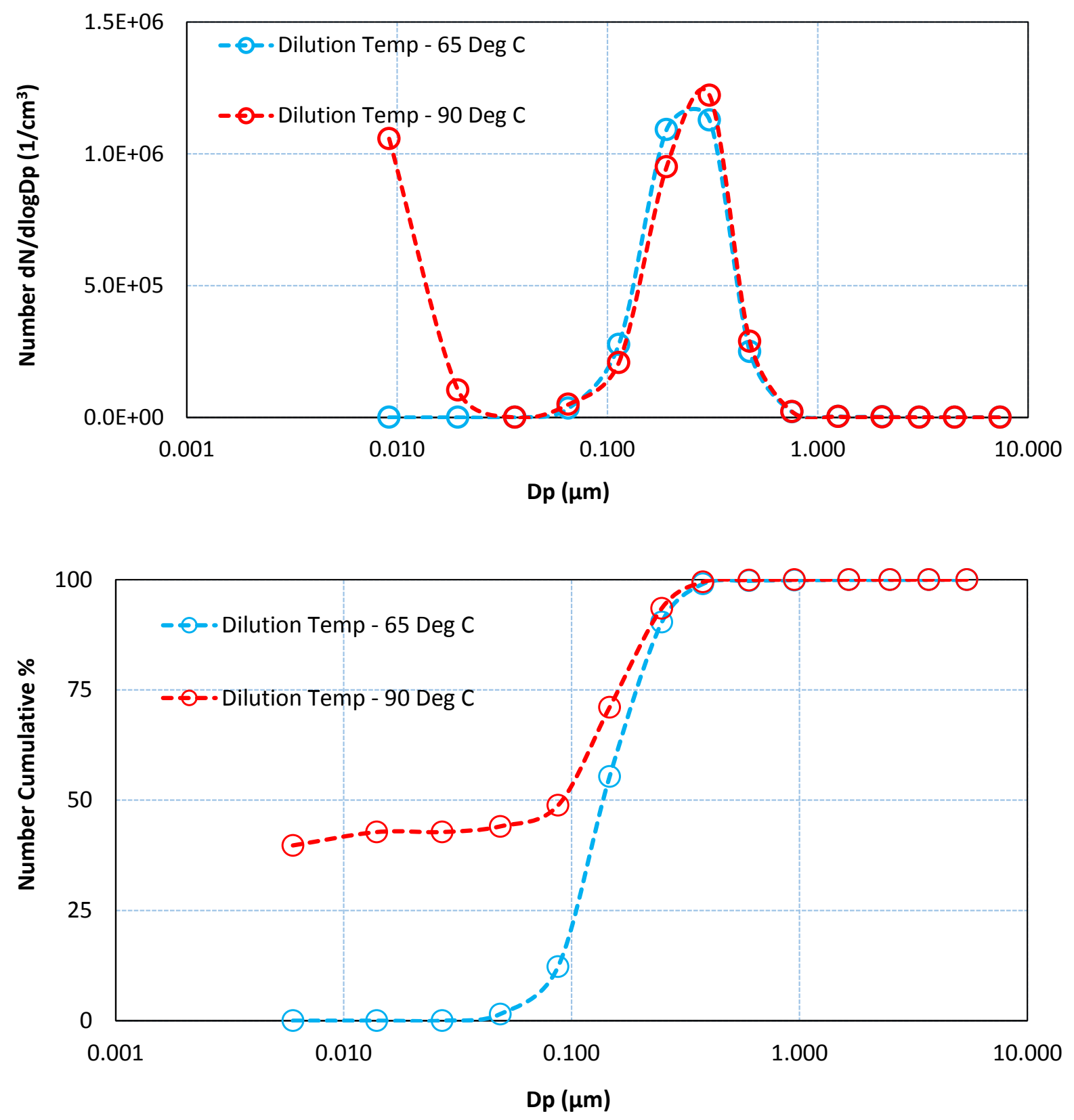

Figure 13. Effect of dilution heating temperature on real-time aerosol number concentrations \& cumulative percentage at wash tower outlet

\subsection{Comparison of PSTU and SSTU Results}

Figure 14 shows the comparison of aerosol concentrations at the PSTU scrubber inlet, and the wash tower outlets of the PSTU and SSTU. It should be noted that parameters, such the dilution ratio and isokinetic sampler nozzle size, were not identical for both wash tower outlet measurements. It can be seen from the number concentration plots that the aerosol concentration 
is very high at PSTU scrubber inlet as compared to the wash tower outlets. This observation is expected, as the wash towers remove a substantial amount of aerosols. The cumulative aerosol percentages reveal that there were less small size aerosol accumulation at the wash tower outlet of the PSTU than that of the SSTU. This inconsistency is likely due to dissimilar process parameters as mentioned above, although further investigation is needed.
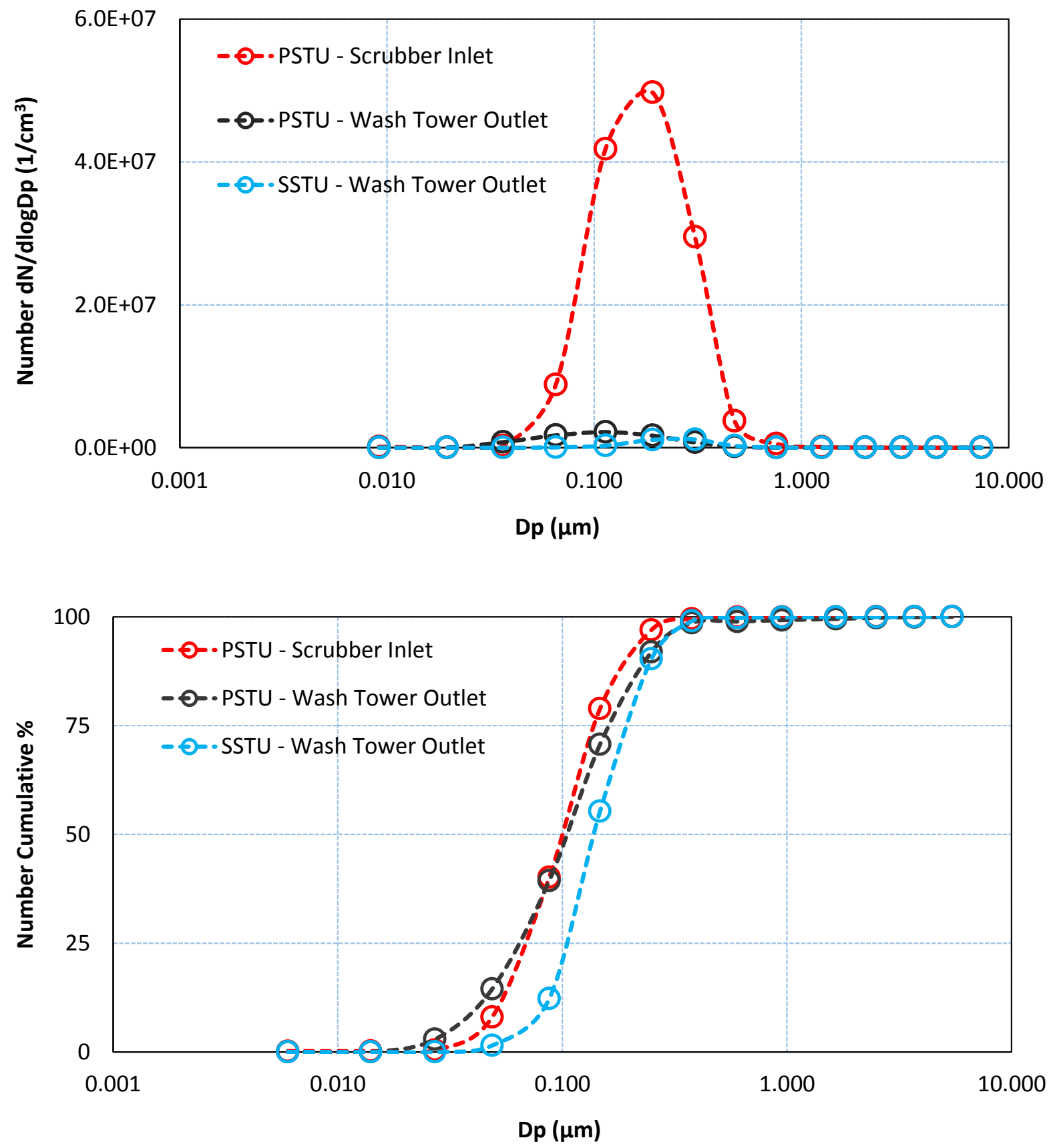

Figure 14. Comparison of real-time aerosol number concentrations \& cumulative percentage 


\subsection{Optical Images}

Optical images of stages 3 and 4 are shown in Figure 15. The upper two images are of substrates collected after the test, and the lower two images are of the back of the impactor jet plates. A regular pattern of collection can be observed. The pattern indicates aerosol collection with very fine solids.

However, at higher stages of aerodynamic diameters, it is believed that the aerosol droplets coalesced in flow eddies and formed larger droplets. Also light yellowish color of the droplets at higher stages indicates the presence of solvent with in the liquids. The images of higher stages 6 and 7 are presented in Figure 16.

The physical appearance of the aerosols and their collection patterns as shown in Figures 15 and 16 are very important because these give us clear picture about the aerodynamic diameter, stage cuts we have determined earlier, effect of coalescence of the aerosols and an estimates of amine emissions with the aerosols. The ELPI measurements only give us electrical signals but these physical information is complementary for real-time aerosol measurements as reported in this manuscript.

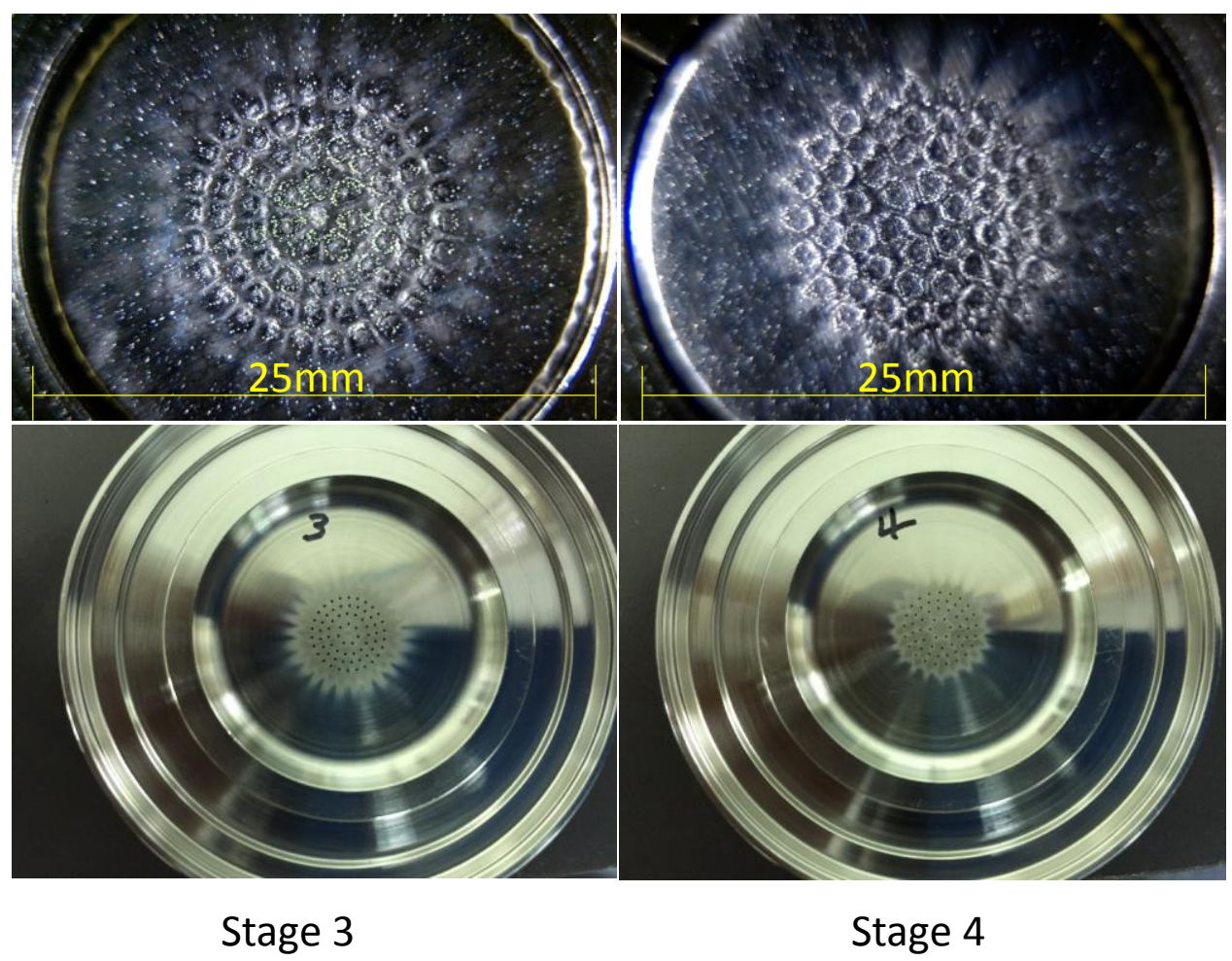

Figure 15. Optical images of stage $3 \& 4$ of ELPI ${ }^{+\mathrm{TM}}$ 


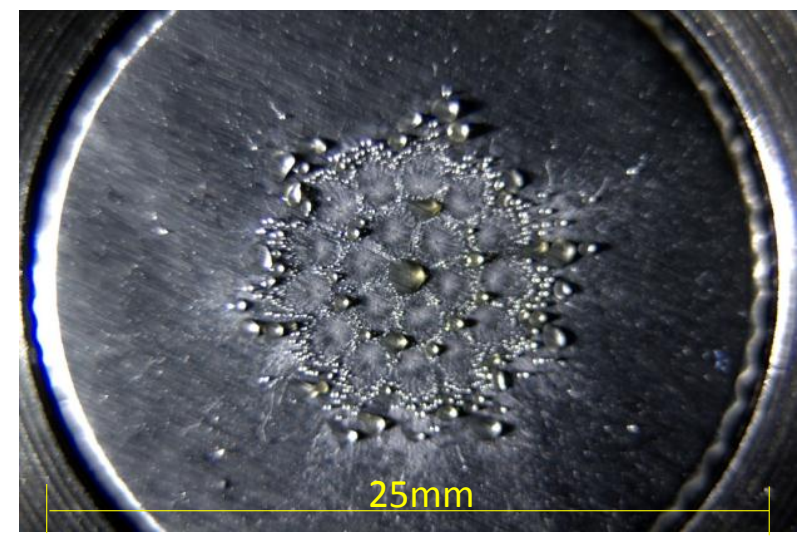

Stage 6

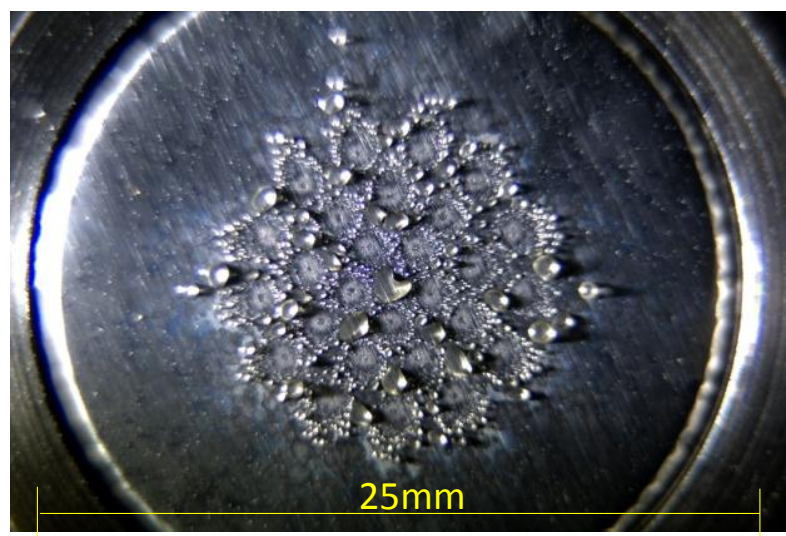

Stage 7

Figure 16. Optical images of stage $6 \& 7$ of ELPI ${ }^{+\mathrm{TM}}$

\subsection{Test-site and Measurement Set-up Photos}

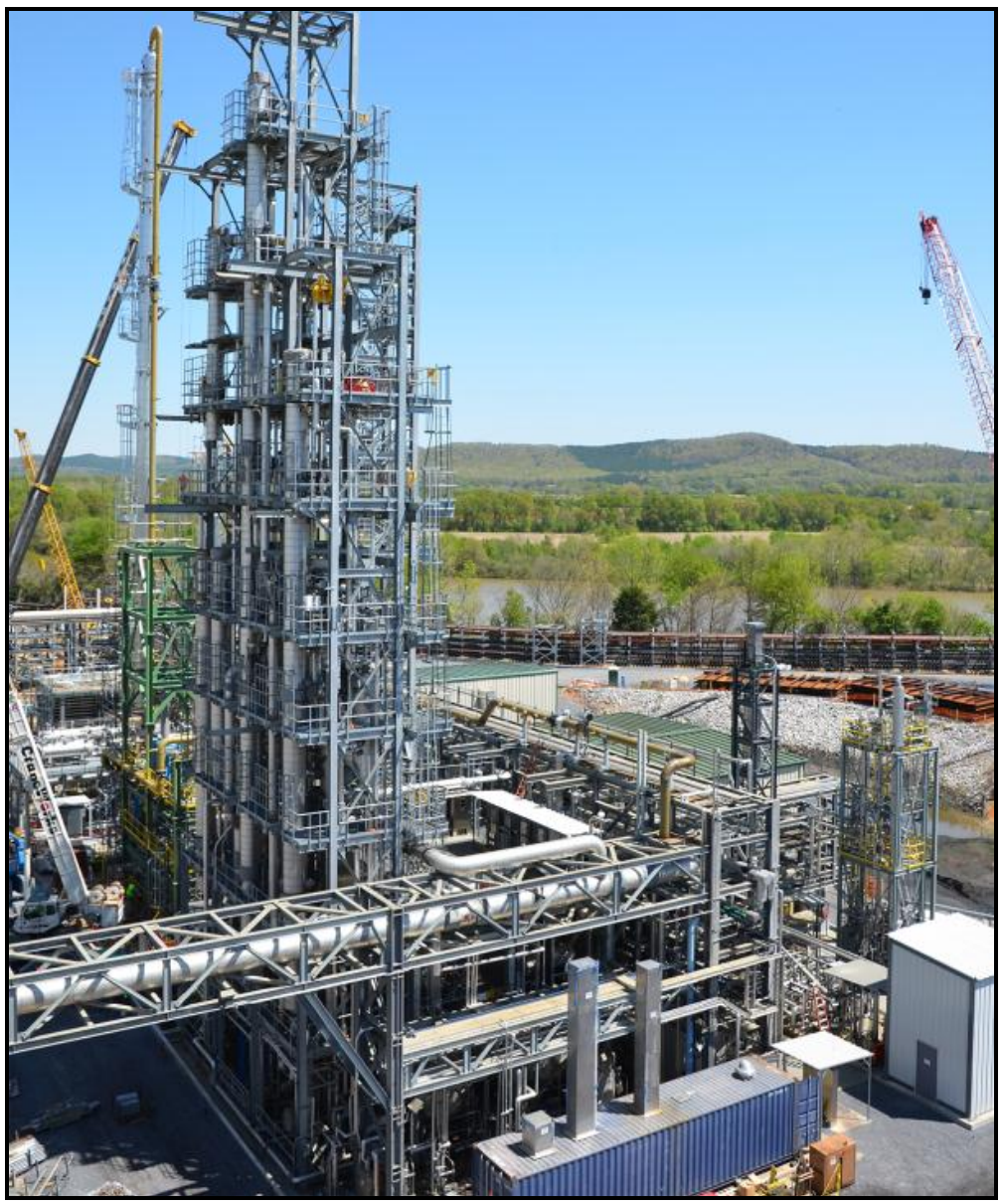

Figure 17. Test site photo at post-combustion $\mathrm{CO}_{2}$ capture facility 


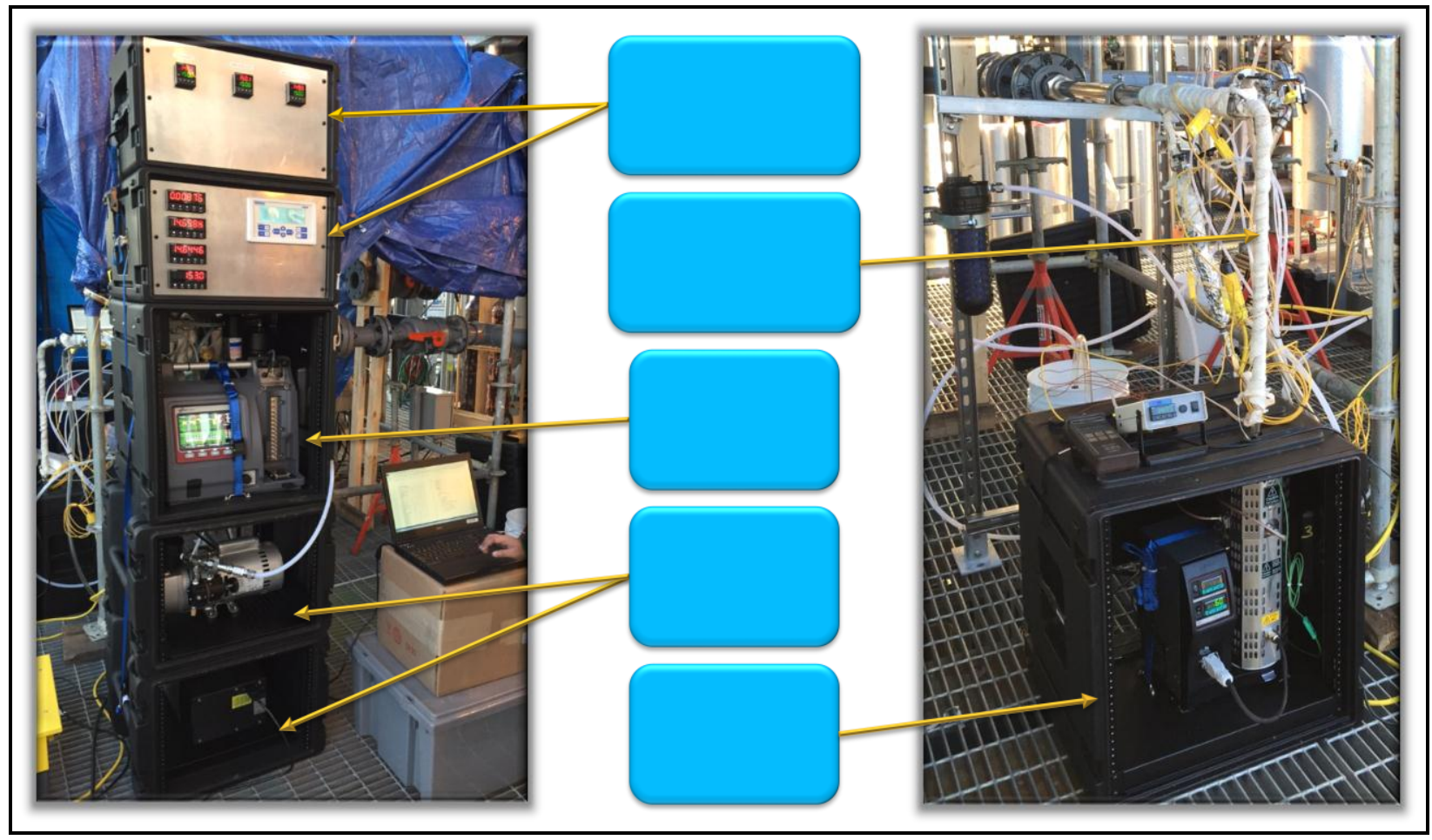

Figure 18. ELPI $^{+\mathrm{TM}}$ measurement set-up; photos taken during one of the test campaigns

\section{SUMMARY AND CONCLUSIONS}

Although amine based post-combustion $\mathrm{CO}_{2}$ capture is a promising technology, studies indicate that amine emissions in the form of aerosols must be controlled for commercial success of this technology. Most of the recent studies characterizing aerosols used simulated flue gas with externally generated $\mathrm{H}_{2} \mathrm{SO}_{4}$, the main precursor for aerosol generation. However, in this study, aerosols produced from flue gas from a commercially dispatched coal-fired power plant was characterized by real-time measurements using isokinetic sampling systems and the ELPI ${ }^{+}$. Measurements were taken on the NCCC's PSTU and SSTU while operating with MEA to quantify the effects of different process changes on aerosol concentration and size.

Aerosol concentration generally was in the range of E+06 to E+07 $\mathrm{cm}^{-3}$ at the PSTU wash tower outlet. These results are in agreement with some of the reported results in current literature. Use of intercoolers decreased the aerosol concentrations measured at the same location. Moreover, aerosol intensity and concentration showed a plume of mist or aerosols in smallest size immediately after the intercoolers were put in service.

The effect of dilution heating temperature was also investigated, which showed a clear shift of increased number concentration towards smaller sizes at high dilution temperature due to accelerated evaporation caused by low relative humidity and elevated temperature of the 
aerosols. The tests at the SSTU however showed that the effect can be diminished if the dilution heating temperature can be set just above the dew point temperature of the incoming gas. This result is important because some of the previous studies have used dilution temperature in the range of $80^{\circ} \mathrm{C}-200^{\circ} \mathrm{C}$.

The effect of absorber beds indicated an increase in aerosol number concentration when the third bed was turned on at the PSTU. This observation needs further investigation in future test campaigns. As expected, the aerosol concentration was very low at wash tower outlet compared to the absorber inlet at the SSTU. Moreover, a small amount of smaller size aerosols at SSTU absorber inlet is observed which are captured in the wash tower. As expected, the aerosol concentrations were very high at the PSTU scrubber inlet compared to the wash tower outlets of the PSTU and SSTU.

It should also be noted that the results represented in this work is based on MEA solvent. Separate detailed investigations will be required for different solvents. Also, it should be noted here that the calibration of the stage cuts of ELPI ${ }^{+\mathrm{TM}}$ shows a maximum deviation of $0.02-0.70 \%$ from the original calibration by Dekati. Overall, these results are very promising and further tests using the $\mathrm{ELIP}^{+}$are planned at the NCCC. These results represent a preliminary basis for developing control measures for aerosol emissions to make amine based post-combustion $\mathrm{CO}_{2}$ capture commercially viable.

\section{ACKNOWLEDGEMENTS}

The U.S. Department of Energy (DOE) is acknowledged for this work. This material is based upon work supported by the Department of Energy under Award Number(s) DE-FE0022596. Also acknowledged are the following organizations: NETL, Southern Company, EPRI, Luminant, American Electric Power, Duke Energy and Cloud Peak Energy. Harry Nortega, Terry Hammond and Todd Snyder are acknowledged for helping in test set-ups and various measurement related activities.

Disclaimer: This report was prepared as an account of work sponsored by an agency of the United States Government. Neither the United States Government nor any agency thereof, nor any of their employees, makes any warranty, express or implied, or assumes any legal liability or responsibility for the accuracy, completeness, or usefulness of any information, apparatus, product, or process disclosed, or represents that its use would not infringe privately owned rights. Reference herein to any specific commercial product, process, or service by trade name, trademark, manufacturer, or otherwise does not necessarily constitute or imply its endorsement, recommendation, or favoring by the United States Government or any agency thereof. The views and opinions of authors expressed herein do not necessarily state or reflect those of the United States Government or any agency thereof. 


\section{ABBREVIATIONS}

$\begin{array}{ll}\text { CPC } & \text { Condensation Particle Counter } \\ \text { DOE } & \text { Department of Energy } \\ \text { ELPI } & \text { Electrical Low Pressure Impactor } \\ \text { HT } & \text { High Temperature } \\ \text { MEA } & \text { Monoethanolamine } \\ \text { MW } & \text { Megawatt } \\ \text { NCCC } & \text { National Carbon Capture Center } \\ \text { PDI } & \text { Phase Doppler Interferometer } \\ \text { PSTU } & \text { Pilot Solvent Test Unit } \\ \text { SSTU } & \text { Slipstream Solvent Test Unit } \\ \text { WFGD } & \text { Wet Flue Gas Desulfurization } \\ \text { WTO } & \text { Wash Tower Outlet }\end{array}$

\section{REFERENCES}

DEKATI® Diluter User Manual: Ver. 5.1. (2014).

DOE Final Report. (2014).

DOE Report. (2012).

E. Chen, S. M. F., D. Sache, Y. Lin, G. T. Rochelle. (2014). Pilot Plant Activities with Concentrated Piperazine Energy Procedia, 63, 1376 - 1391.

ELPI+TM User Manual: Ver. 1.50. (2015).

G. Rochelle, E. C., S. Freeman, D. Van Wagener, Q. Xu, A. Voice. (2011). Aqueous piperazine as the new standard for CO2 capture technology. Chemical Engineering Journal, 171, 725-733.

J. Mertens, C. A., P. Rogiers, L. Brachertb, P. Khakharia, E. Goetheer, K. Schaber. (2014). A wet electrostatic precipitator (WESP) as countermeasure to mistformation in amine based carbon capture. International Journal of Greenhouse Gas Control, 31, 175-181.

J. Mertens, L. B., D. Desagher, B. Schallert, P. Khakharia, E. Goetheer. (2014). Predicting amine mist formation based on aerosol number concentration and size measurements in flue gas Energy Procedia, 63, 893-901.

J. Mertens, L. B., D. Desagher, M. L. Thielens, P. Khakharia, E. Goetheerc, K. Schaber. (2014). $\mathrm{ELPI}^{+}$measurements of aerosol growth in an amine absorption column. International Journal of Greenhouse Gas Control, 23, 44-50.

José D. Figueroa, T. F., Sean Plasynski, Howard McIlvried, Rameshwar D. Srivastava. (2008). Advances in CO2 capture technology-The U.S. Department of Energy's Carbon Sequestration Program. International Journal of Greenhouse Gas Control, 2(2), 9-20.

L. Brachert, J. M., P. Khakharia, K. Schaber. (2014). The challenge of measuring sulfuric acid aerosols: Number concentration and size evaluation using a condensation particle counter (CPC) and an electrical low pressure impactor (ELPI+). Journal of Aerosol Science, 67, 21-27. 
L.M. Romeo, J. C. A., J.M. Escosa, J. Paño, A. Giménez, A. Sánchez-Biezma, J.C. Ballesteros. (2008). Oxyfuel carbonation/calcination cycle for low cost CO2 capture in existing power plants. Energy Conversion and Management, 49(10), 2809-2814.

P. Khakharia, J. M., T. J. H. Vlugt, E. Goetheer. (2014). Predicting Aerosol Based Emissions in a Post Combustion CO2 Capture Process Using an Aspen Plus Model. Energy Procedia, 63, 911-925.

P. Khakharia, L. B., J. Mertens, A. Huizinga, B. Schallert, K. Schaber, T. J. H. Vlugt, E. Goetheer. (2013). Investigation of aerosol based emission of MEA due to sulphuric acid aerosol and soot in a Post Combustion CO2 Capture process International Journal of Greenhouse Gas Control, 19, 138-144.

Qi, G. W., Yanbing; Estevez, Luis; Duan, Xiaonan; Anako, Nkechi; Park, Ah-Hyung Alissa; Li, Wen; Jones, Christopher W.; Giannelis, Emmanuel P. (2011). High efficiency nanocomposite sorbents for $\mathrm{CO} 2$ capture based on amine-functionalized mesoporous capsules. Energy \& Environmental Science, 4(2), 444-452.

R. K. Srivastava, C. A. M., C. Erickson, R. Jambhekar. (2004). Emissions of sulfur trioxide from coal-fired power plants. Journal of the Air \& Waste Management Association, 54, $750-762$.

Schaber, K. (1995). Aerosol Formation In Absorption Processes. Chemical Engineering Science, 50, 1347-1360.

World Energy Outlook. (2011). 